should give the strongest reflection, owing to a difference in density produced by stamping," and to the brassworker's solution, not oniy are the mirrors not stamped, but cast; but it is the thicker parts, those which stand out on the back in highest relief, which reflect the most light. I have one on the back of which there are two large characters as it were laid upon a background of trees. These letters have been carefully ground flat and polished like the front. Their figures not only appear more distinctly than those of other less highly raised adornments, but actually, in the sun, throw off a brilliant white light, which contrasts very markedly with the comparatively subdued spectrum from the rest of the plate.

Is it possible that there may be some difference in molecular arrangement during the consolidation of the melted metal in the thicker (relieved) and other parts of the plate? And yet, the thick rim of the mirror does not reflect a rim of light.

One of my specimens has suffered a little oxidisation, and I observe that this appears on the face to follow certain of the larger masses of relief on the back. This mirror does not "show the pattern through," but there is a curious bright rim reflected from the edge of each scar of injured surface.

Manchester

R. D. DARBISHIRE

\section{Colour-Sense in Birds}

As the fact of the preference of sparrows for yellow crocuses still excites interest and requires explanation, perhaps you will allow me to call attention to the following remarks of Gilbert White in his "Observations on Nature" :-

"Birds are much influenced in their choice of food by colour, for though white currants are a much sweeter fruit than red, yet they seldom touch the former till they have devoured every bunch of the latter."

The obvious criticism that the craving for sweets which distinguishes the human biped is not equally predominant among his feathered friends, and conscquently, that their selection of the less sweet but more highly coloured fruit may be due to some taste other than the esthetic, does not detract from the importance of White's generalisation that birds are much influenced in their choice of food by colour-a generalisation which, there is no reason to doubt, was based upon his own keen and repeated observation.

Beddington Park

\section{OUR ASTRONOMICAL COLUMN}

VARIABLE STARS.-The following are Greenwich mean times of visible geocentric minima of Algol, for July, August, and September, according to the elements adopted by Prof. Schönfeld :-

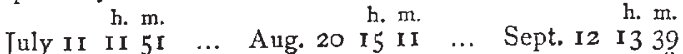

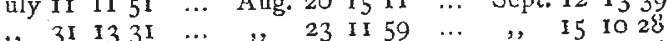

$$
\begin{aligned}
& \text { Äug. } 3 \text { 10 } 20 \text {... Sept. } 9 \text { 16 } 5 \text { I } \ldots \text {... }
\end{aligned}
$$

Minima of S Cancri occur on September 8 at $15 \mathrm{~h}$. Im., and September 27 at $14 \mathrm{~h}$. $14 \mathrm{~m}$ :

A minimum of Mira Ceti will fall on July 23, according to Argelander's formula of sines, the same perturbations being applied as in the case of the maximum of the year, which is computed to occur November $9 \%$.

Mr. John Tebbutt, writing from Windsor, N.S. Wales, on April 13, states that in consequence of remarks on the probable variability of $\mu$ Doradûs, in NATURE, vol, xv. pp. I4 and $28 \mathrm{r}$, he examined the star on February 26 , and March I4, and found it of the 8th magnitude. There is a star, estimated 9th magnitude, about thirty seconds of time west, and twelve seconds north of it. With such an instrument as was employed by Lacaille at the Cape of Good Hope in $175 \mathrm{I}, \mu$ Doradûs, with its present brightness, would hardly have been visible. Lacaille calls it a fifth magnitude.

Minor Planets AND COMETS OF SHORT PERIOD.Dr. von Asten, in the course of his recent researches on the motion of Encke's comet, found that, although in the interval 1819-68 the comet had experienced in each period of revolution an almost exactly equal amount of acceleration, and that this might be attributed to the existence of a resisting medium, yet in order to connect the last two appearances in $187 \mathrm{I}$ and 1875 with the previous ones, it is necessary to have recourse to the hypothesis of an extraordinary perturbation which, in the period $1868-7 \mathrm{I}$, counteracted the influence of a resisting medium. For certain reasons Dr. von Asten is led to conjecture that about the middle of the year 1869 , when the comet was in the region occupied by the numerous group of small planets (the radius vector being about 3.2 ), it made so close an approach to one of these bodies, as yet undiscovered, that a sensible effect on the comet's mean motion was the result.

In connection with this hypothesis it may be interesting to note that the late Prof. Hubbard, whose masterly in. vestigations on the motion of Biela's comet appeared in Gould's Astronomical Fournal, came to the conclusion that the separation of the comet into two distinct bodies, by whatever cause effected, took place in all probability in a heliocentric position corresponding to abuut longitude $318^{\circ} \cdot 6$, latitude $+12^{\circ} \circ$, with radius-vector 4.36 , which position the comet occupied in November, 1844 (Ast. Fourn., No. I40). It is stated in some works that the comet in 1846 separated under the very eyes of astronomers; nevertheless it is upon record that the companion was first recognised on December 29 by Herrick and Bradley at New Haven, but was not ayain seen until Maury refound it on Jannary 13 ; and its not having been remarked when the comet $\mathrm{w}$ is first glimpsed in the Northumberland and other powerful telescopes may well have been owing to distance and faintness.

A radius vector of 4.36 would, until quite recently, have been considered as placing the comet rather outside the probable superior limit of distance of the minor-planet group, but the discovery of Hilda by $M$ Palisa in $\mathrm{N}_{0}$ vember, I 875, considerably extended the limit, this body in aphelion being distant from the sun $4^{*} 6$. Although the separation of Biela's comet, if it really took piace at the epoch assigned by Prof. Hubbard, could not have been owing to an encounter with this particular planet, yet the position indicated for the occurrence is clearly a possible one for a meeting with an unknown member of the group. In saying this much we are of course aware that the separation may have been owing to a very different cause, indeed it might be supposed that such a rencontre would have left a more sensible effect upon the mean motion of the comet.

METEORIC FIRE-BALLS IN AMERICA.-Prof, Daniel Kirkwood in a communication to the American Philosophical Society, on March I6, gives some particulars of meteoric fire-balls which appeared in unusual number in the United States in the latter part of 1876 and beginning of the present year. The circumstances attending the appearance of eight conspicuous meteors are included : the dates were 1876 , July 8 (two fire-balls), December 16 and 21 , January 3,20 , and 23 , and February 8 . The train of the larger meteor of July 8 was visible at least forty minutes, the mass having been apparently dissolved or dissipated in the latter part of its track; the motion about the sun was retrograde, but sufficient materials were not forthcoming for determining the orbital velocity or the nature of the orbit. The fire-ball of December 16 had been visible but a few seconds near San Francisco when it apparently plunged into the Pacific at no great distance from the shore, the fall being followed by a loud detonation. The meteor of December 2I was remarkable for the length of its track, between 1,000 and 1,100 miles, one of the longest upon record, and, moreover, the track would appear to have been somewhat curved. When crossing Indiana the principal fire-ball was followed by a train of smaller meteors, many of which exceeded Venus and Jupiter in apparent magnitude; the breadth of the cluster, as seen from Bloomington, was $3^{\circ}$, and the length at least $20^{\circ}$, from which Prof. Kirkwood concludes that the true diameter was five miles; and the length about forty miles; several explosions occurred during the passage of the meteorite over Indiana and 
Ohio, and a fragment weighing about twelve ounces, fell upon a farm near Rochester, Indiana, a part of it being secured by Prof. Kirkwood. The body is described as "peculiar in its structure; being pisolitic and remarkably friable." It is inferred that no part of the mass could have escaped out of the atmosphere. The aerolite of January 23 , or rather a portion of it, after the final explosion, reached the earth in Kentucky, and is now in the collection of Dr. J. Lawrence Smith, of Louisville. The report is stated to have resembled discharges of heavy ordnance, in such close succession, that the different discharges were barely distinguishable; height at first appearance about seventy miles.

The Transit of VenUs, 1882.-In Astron. Nach., Nos. 2I33-4, we have another calculation of the elements of this transit from M. Leverrier's Tables; it is by Dr. Deichmüller, of the Observatory at Bonn, who has followed Prof. Oppölzer's method for the necessary data for reduction of the observations which are interpolatell down to short intervals in Paris time. There are special calculations for certain principal stations.

\section{THE LAND OF HISSAR AND KOLAB}

$T \mathrm{HE}$ eastern part of the dominions of the Emir of Bokhara is the belt of land between $37^{\circ} 30^{\prime}$ and $39^{\circ}$ N.L., and $67^{\circ}$ and $71^{\circ}$ E.L., borderea on the north by the now Russian province of Samarkand and the Karategin, and on the south by Afghanistan (the Balkh, Kunduz, and the Badakshan districts). It has hitherto been all but totally unknown. M. Maïeff, after having, together with Lieut. Vishnevsky and M. F. Schwarz, thoroughly explored it in 1875, gives us a description of the land of Hissar and partly that of Kolab (Isvestia of the Russ. Geog. Soc., 1876, 4 ih fasc.), with an elaborate map, based on numerous determinations of latitudes and longitudes, surveys, and barometrical measurements of heights.

Two great rivers running east and west, the upper Zerafshan on the north, and the Pandsh, or Upper Oxus, on the south, are the natural boundaries of the country. A third river, the Shehrsebz, running in the same direction under $39^{\circ}$ N.L., borders its north-western corner, and a mass of high table-lands, the Pamir, rises to the east of the Kolab district. The whole land is filled with mountains belonging to the Tian Shan system. Two main ridges, which both run north-east to south-west, and are divided by the broad valley of the Surhan, ${ }^{x}$ form the backbones of this hilly tract. Secondary ridges, either parallel to the main ones, or spreading out of them, fill the country. But at their western extremities, the mountain ridges are farlower than we know them to be in the east. Thus, the ridge between the Shehrsebz and the Surhan, now called the Hissar Ridge, ${ }^{2}$ rising above the snow-line in its eastern parts, is far lower in the western; and its highest pass, Ak-rabat, is but 4,590 feet high, whilst other passes are as low as from 2,200 to 3,600 feet above the sea-level. The second main ridge, lying to the east of the broad Surhan valley and running between it and that of the Vaksh, seems to be higher, but yet far below the highlands of Kokand or of Eastern Turkestan. Besides, tne highlands are deepiy cut into by large and broad valleys which have in their lower parts a prevailing direction south by west, running thus to the Oxus. The northwestern slope of the Hissar ridge is drained by only one river, the Guzar-daria, an affluent of the Shehrsebz; but instead of being an insigniticant stream, as on our present maps, it appears as a mighty river fed by the perpetual snows of the Sengri-dag, and its upper shores are occupied by a numerous population. East of the'Hissar ridge we see a series of broad well-peopled valleys. First, that of the Snir-abad, from about 2,500 to 900 feet high, with the towns Derbent, Baisun, and Shir-abad. Next, Tupalik on Mr. Arrowsmith's map in the foumn. Roy. Geog. Soc., I875.
Tupalan is the name of one of the upper affuents of the Surhan.

2 Its local narnes are Bash-hurd, Baisun-tau, Meshai-kenteli, \&c. the valley of the Surhan river which, as well as the Guzar and the Shir-abad, rises in the snow-covered ridge MeshaiKentely, and receives many affluents. Some time before its annexation to Bokhara, this valley was a centre of the political life of the country, and, going back in its history, we come to a time when-a local tradition says-the population was so dense that a cat could travel upon the roofs of the dwellings from Denau to the Amu. Now the population is concentrated in the upper, better. watered parts of the valley, where we find the towns Kara-tag, Sary-djui, Yourchi, and Denau. Further east we have the valley of the Kafirnagan (the Ramid of Ibis-Dast), the source of which is about Paldorak, this river being second in size to the Surhan. An enlargement in the upper parts of its valley, running east and west, is well peopled, and contains the towns Hissar, Fyzabad, Kafirnagan, and Doshambe. Then, below Hissar, the river enters a deep ravine, Pavi-Duldul (the foot of the Duldul, the mythic horse of Ali), at the issue of which is the town Kahadian ( 460 feet high), close to the Amu-daria.

Further east, beyond the second main ridge alluded to above (its local names are-By-katyn, Mazi-melek, Avantau, \&c.), we have the basins of the Upper Oxus, i.e., of the Vaksh (or Surhab) and the Pandsh, which both, M. Maïeff observes, must be considered as the sources of the Oxus. The former rises in the glaciers of the Alai-ridge and runs, under the name of Kyzyl-soo, on the Pamir table-land. After having received a great affluent, the Muk-soo, the river bears the name of Surhab and enters the Bokhara dominions through an impracticable deep ravine, at the well-known bridge Pooli-sengui. After a short course among mountains it soon emerges on a piain some 500 feet high. Divided into many branches, the main one about 180 yards broad, it runs to its junction with the Pandj near Kurgan-tube. Only one of the affluents of the Pandj, the Kchi-Surhab (little Surhab), was explored by M. Maïeff; it is formed by two rivers, the Baldshoan and Kolab, the valley of the latter being well peopled and cultivated, notwithstanding the extensive marshes which have given their name to the town, $\mathrm{Kol}$ ab.

The population of the country consists of Usbecks and Tadjicks, the former occupying mostly the lower and better parts of the valleys, having driven the Tadjicks back to the upper parts. The banks of the Amu-daria, and especially the western parts of the country, are mostly peopled with. Kungrad-Usbecks, the Tadjicks appearing more numerous to the east. The towns contain, as usual, a very mixed population. The lower parts of the Vaksh and the Kolab valley are mostly peopled by Usbecks of the Katagan tribe. Some Kirgises have begun to found settlements in the lower parts of the Vaksh and Pandsh valleys; and some miserable Turkomans are strewn among the Usbecks on the shores of the Amu. Jews, Hindoos, and Afghans form a very small percentage of the population.

As to the climate of the country, it is easy to perceive that it must be comparatively mild. In the higher parts of the Kafirnagan valley there are occasionally falls of snow about two feet deep, but the lower parts of the valleys have a mild, rainy winter. Figs grow at Shirabad unsheltered during the winter. All kinds of corn and fruits common to Central Asia are produced in abundance. Cotton, however, is cultivated only in Shirabad, owing to facility of export to Karshi (on the Shehrsebz). Rock-salt is worked in the neighbourhoods of Guzar and on the Upper Vaksh, but it must be found also elsewhere, the salt springs being numerous. Two gold mines are known on the shores of the Vaksh, and richer ones are reported to exist in the Darvaz.

The country is under the dominion of the Emir of Bokhara, being administered by nine becks, vassals to the emir, seven in the Hissar district, and two in that of Kolab, 